\title{
An occupancy-based strategy employing computer vision for reducing cooling energy consumed in buildings
}

\author{
Rania Atef Mohamed AlQadi ${ }^{1}$, Alaa Zaghloul ${ }^{2}$, Shereen Aly Taie ${ }^{3}$ \\ ${ }^{1,3}$ Department of Computer Science, Faculty of Computers and Information, Fayoum University (FU), Egypt \\ ${ }^{2}$ Department of Computer Science, Faculty of Information Technology, Misr University for Science and Technology
}

(MUST), Egypt

\begin{tabular}{l} 
Article Info \\
\hline Article history: \\
Received Aug 30, 2020 \\
Revised Mar 20, 2021 \\
Accepted Apr 30, 2021 \\
\hline
\end{tabular}

\section{Keywords:}

Computer vision

Energy savings

Human detection

Occupancy controls

\begin{abstract}
The energy expended to cool the occupied areas by air conditioners represents a substantial share of the total energy exhausted in buildings. Therefore, developing strategies to reduce this energy is crucial. One of the preponderance strategies adopted to depreciate energy consumption in buildings is the occupancy-based strategy. In this research, an innovative model was established to achieve the goal of reducing cooling energy consumed in buildings based on occupancy-based combined with a constant temperature setpoint strategy in two phases, and each phase engrosses in 20 days. Phase one is to identify the extent of cooling energy employed according to the use of room occupants and its costs in consumption was $276.01 \mathrm{kWh}$ after completion of this phase. Sequentially, constructing phase two intended to reduce cooling energy consumption by employing an automatic air-conditioner (AC) control strategy relying on an improved human detection algorithm with a $25^{\circ} \mathrm{C}$ as temperature setpoint, resulting in $112.45 \mathrm{kWh}$ of consumption. To complement the motives for elaboration, the human detection measurement using you only look once (YOLO) improved by applying pre-processing algorithms to reach an average human detection enhancement of $21.2 \%$. The proposed model results showed that potential savings associated with the embraced strategy decreases by more than anticipated as the amount of reduced energy reached 59\% savings.
\end{abstract}

This is an open access article under the CC BY-SA license.

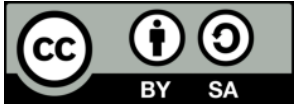

\section{Corresponding Author:}

Rania Atef Mohamed ElQadi

Department of Computer Science

Faculty of Computers and Information

Fayoum University, Fayoum, Egypt

Email: rania_a_elqadi@cic-cairo.com

\section{INTRODUCTION}

Energy consumption has increased speedily worldwide causing the depletion of energy resources and a negative environmental impact. At present, the buildings sector consumes an extensive proportion of aggregated energy and responsible for a significant part of $\mathrm{CO}_{2}$ emissions globally [1]. Until the total energy consumption of the buildings sector reached $40 \%$ of the total energy consumed [2]. To be more specific, the cooling and heating framework inside the buildings have the largest share of this consumption, in particular $50 \%$ of the power consumption [3]. Thus, reducing energy consumption is a critical issue. Former researchers demonstrated that a massive proportion of energy is wasted in unoccupied areas [4].

As a consequence, information about space occupied essentially to reduce energy consumption. In numerous countries including Egypt, the electricity demand has increased dramatically to overcome the peak that led to frequent power outages, especially in the summer season. In Egypt, one temperature increases 
above $35^{\circ} \mathrm{C}$ results in the consumption of $100 \mathrm{MW} / \mathrm{h}$, meaning that the temperature rises to $42^{\circ} \mathrm{C}$ increases consumption to $800 \mathrm{MW} / \mathrm{h}$, which is comparable to a heat station estimated at 2 billion EG and need to be established for about four years [5]. The dependence on electronic equipment in Egyptian buildings has increased significantly over the past years as a consequence of the long summer season leading to a significant rising in energy consumption. For instance, between 2006 and 2010 sales of air conditioning units and fans increased significantly to reach 766 thousand units per year with an increase in this percentage every year.

AC systems expend around $12 \%$ of the produced energy from the power stations, consuming $22 \%$ of overall Egypt's energy production [6]. About 40\% of the energy in Egypt consumed by the building sector [7]. The Egyptian government seeks to implement the integrated energy strategy, which seeks to reduce energy demand [8]. The idea of reducing energy consumption in buildings is not only affected by appliances consumption but probably also affected by human behaviors of energy use and the fast development of technology. Smart grid systems perform an energy audit that aids in determining energy efficiency opportunities that lead to better results and continuity of operations efficiently in buildings [9]-[11]. The interactivity between occupants in buildings and energy-consumption in their environment requires improvements, such as reinforce conventional public-use buildings with several technologies, like smart adaptors, energy analyzers, an occupant aware, and decision support interfaces introduced by the GreenSoul project. The GreenSoul structure strengthened by embracing GreenSoul-ed devices, which decrease energy consumption by interacting with other devices, smart metering equipment, and very importantly, with eco-aware users [12], [13].

Most modern strategies to reduce cooling power rely on temperature control or occupancy-based strategies. The Kingdom of Saudi Arabia (KSA) is one of the countries with a hot climate during the summer season, so reliance on air conditioners is essential. Moncef, investigates various temperature control strategies with temporary occupancy patterns associated with Saudi households. In particular; 1) Constant setpoint temperature for all rooms; 2) Raising the temperature setpoint in the limited occupied spaces; and 3) $24{ }^{\circ} \mathrm{C}$ temperature setpoint merged with occupancy patterns schedules in the occupied spaces. They inferred outstanding energy savings evinced by higher set-point temperatures for the cooling system in hot climates areas (38.7\% savings of total annual consumption) [14]. In this research, they perceived that energy efficiency increases when choosing temperature setpoint based on the external temperature and they can achieve savings from $10 \%$ to $37 \%$ of energy based on climate [15]. To scrutinize the advantage of augmenting indoor thermostat heating and cooling setpoints to save energy in the office building. Holy et, conducted a simulation hilled in six offices on seven climate zones concerning indoor satisfaction level temperature by expanding the cooling setpoint and decreasing the heating setpoint autonomously. By raising the cooling setpoint from 22.2 to $25^{\circ} \mathrm{C}$ temperature, they demonstrated $29 \%$ savings of cooling energy [16].

Other researchers' strategies depend on occupancy measurement. An adoption Hvac strategy depends on the indoor occupancy rate $(\mathrm{R})$ shows a $15 \%$ reduction in energy consumption when preventing the air-conditioning system from contributing surplus cold air to the occupied space when the number of occupants is lacking [17]. Nikdel et al. in small office building models based on American society of heating, refrigerating and air-conditioning engineers (ASHRAE) standard, investigates constant temperature, programmable thermostat and setpoint temperature based on the existence of at least one occupant merged with occupancy scheduled in five different climates zones. Results elucidated that occupancy-based scenarios consume minimal energy than the remaining scenarios [18].

Accordingly, most of the strategies followed to reduce the cooling energy consumed in buildings, considered to be fixed, do not interact with changes within the building environment, and often lack the combination of both temperature setpoint and occupancy information. Therefore, relying on the occupancybased strategy requires new strategies, especially to reach the changing patterns of occupancy continuously. And differ from occupancy-based schedule strategies or obtaining occupancy information using the traditional sensor methods to ensure the accuracy of the occupancy information that considerably helps in reducing the cooling energy consumed.

The contribution of this paper innovated a model that embraces an effective strategy to reduce cooling energy consumption based on occupancy-based combined with a temperature setpoint strategy. The adopted model was established on an automatic AC control strategy dependent on real-time streaming data of the occupancy information using an improved YOLO human detection algorithm combined with a $25^{\circ} \mathrm{C}$ temperature setpoint control. The proposed model aims to spare much cooling energy consumed as far as reasonably expected of buildings. 


\section{RESEARCH METHOD}

To show the effectiveness of occupancy-based increasing of setpoint temperature on the energy and the consumption of the building. A sample model of a room was taken and simulation results concluded.

\subsection{Model architecture}

Building architecture: The applied model is carried out into a typical Egyptian single-family residence in a 6-floor building based on Egyptian code to improve energy efficiency in residential buildings which were presented by Housing and Building National Research Centre in Egypt in 2005 based on international standards (ASHRAE 90.1) [19], [20].

Hardware architecture: To finish the objectives of introducing this model and get some significant data, some inexpensive cost hardware embraced:

- Arduino Uno/1.0 board.

- Sensors current transformer-13 (SCT-013) to measure consumed cooling energy.

- Infrared (IR) emitter sensor to control AC.

- Detection humidity temperature (DHT11) sensor to measure temperature degrees.

- Camera with night vision capability.

Temperature control: The climate of Egypt is considered warm in the summer season and susceptible to changes, with continuing to increase the proportions of temperature, the thermal conditions suitable for living and practicing various work activities in buildings will be imbalanced [21]. Many researchers have embraced comfortable temperature regulation of the human, the recommended cooling temperatures, taking into account the nature of the room activity, range from $20.5^{\circ} \mathrm{C}$ to $24.9^{\circ} \mathrm{C}$ [22] Accordingly, the cooling temperature set-point was determined to be $25^{\circ} \mathrm{C}$ throughout the proposed model implementation phases. The proposed model was previewed in the summer season between July and August to note the amount of energy consumed in cooling that can be saved.

Human detection based on deep learning algorithms: Researchers have adopted many devices such as passive infrared (PIR) sensor, ultrasonic sensor, sound sensor, smart device-based sensing, and camera sensor. For improving the performance of applications that require accurate occupancy information to improve energy consumption rates. Cameras are significant devices that answer their presence inside any building, conferring much important information such as presence, location, and tracking. Thereof, giving sufficient information about zone occupancy assistance in controlling heating and cooling devices [23], [24]. One of the key challenges in this work is to identify a suitable object detection algorithm for the indoor environment to detect the presence of humans.

A significant improvement in methods of object detection appeared based on the use of convolution neural networks (CNNs) in recent years. Newfangled algorithms concerning object detection which depend on CNNs such as faster R-CNN [25], single shot multibox detector (SSD) [26], and you only look once (YOLO) [27]. With the aim of precisely adjudicate these algorithms, the working environment for all of them is standardized, is being as; graphics processing unit (GPU) is Nvidia Tesla K80, RAM of GPU is 12 GB, random access memory (RAM) is $13 \mathrm{~GB}$, and operating system is Ubuntu 18.04.3 LTS. This work focus is on the test time performance and mean average precision (mAP) of these algorithms. Figure 1 describes the framework of SSD and faster regional convolutional neural network (RCNN) algorithms [28], [29].

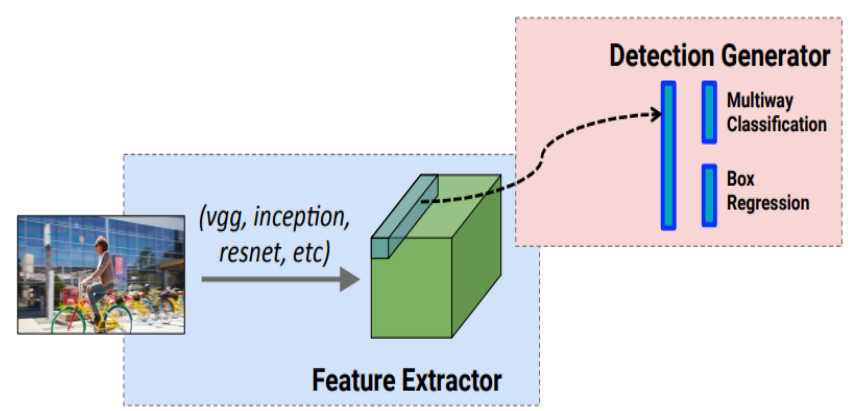

(a)

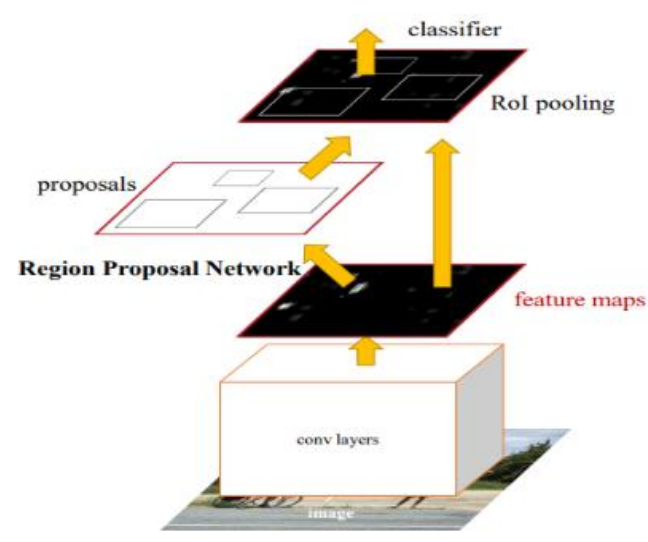

(b)

Figure 1. SSD and faster RCNN frameworks description, (a) SSD framework [28], (b) Faster RCNN framework [29] 
SSD technique utilizes a single feed-forward convolutional network to directly predict classes an anchor offsets, dispensing with a second stage per-proposal classification operation. At variance with fasterRCNN object detection occurs in two stages: 1) Region proposal network and 2) region of interest (ROI) pooling layer, as shown in Figure 1. YOLO proposes the essential endowment for real-time detection of full images and webcam. It is at odds with the region-based algorithms. Therefore, a single CNN determines the bounding boxes with their class probabilities [28], [30]. Table 1 illustrates the test time performance, mean average precision (mAP), and frame per second (FPS) of the object detection algorithms.

According to the evaluation mentioned in Table 1, it is observed that YOLOv3 is very fast, possesses a standard precision with the best two-phase identifiers. The aforementioned makes it a remarkable object detection model for our proposed model. To achieve the best result in detecting the human factor using YOLO, a pre-processing step was combined to improve the detection results.

Table 1. Comparison between faster-RCNN, SSD, and YOLOv3 algorithms

\begin{tabular}{cccccc}
\hline Method & Train & Test & mAP & FPS & Inference time (ms) \\
\hline Faster-RCNN & COCO Trainval & Test-dev & 55.7 & 5 & 200 \\
SSD & COCO Trainval & Test-dev & 50.4 & 8 & 125 \\
YOLO & COCO Trainval & Test-dev & 57.9 & 20 & 51 \\
\hline
\end{tabular}

When starting work with YOLO, it was noted that the rate of detection of the human factor in which video was captured in night vision at some angles is helpless and in some cases lacking. Therefore, some adjustments have to be made to get the best results. With experience, it was observed that the application of pre-processing techniques for the captured image in night vision mode considerably improved the ratio of detection of the human factor using YOLO. Especially in those pictures where the human is located in a light-poor area. To test the application of the pre-processing algorithms, the following set of steps were applied:

- Step 1: The video split at a rate of 3 frames per second.

- Step 2: Test and record the human detection rate using YOLO.

- Step 3: Pre-processing algorithms will be used made up of two phases,

a. Apply the dehazing algorithm on the image.

b. Apply histogram equalization algorithm on dehazed image.

To clarify the previous steps, the video in the night lighting split into a set of frames with a rate of 3 frames per second to show the difference in movement during one second. Subsequently, the human detection rate on the tested image using YOLO without any advance adjustment to the image is recorded. As illustrated by pre-processing algorithms used, the first pre-processing step is to apply the dehazing algorithm on the image to restore illumination. In the second pre-processing step, the resulted image of applying the dehazing algorithm applied to histogram equalization to adjust image contrast.

After completing the previous steps, the image is ready to reveal the human factor present in it using YOLO. The results are distinctly illustrated in the RESULT AND DISCUSSION section. Consequently, the proposed model constructed on the above-mentioned architecture model, and this model is composed of combination phases illustrated in the following sections.

\subsection{Model phases}

Phase one: This phase target enumerating the actual electric energy utilized by the air conditioner of the cooling aforementioned area without any conditions according to the normal use of the room's occupants. The cooling energy used by AC was measured for 20 days, measuring every day's cooling consumption. Throughout the day, six different hours manipulated energy measured, adjusting air conditioner temperature to $25{ }^{\circ} \mathrm{C}$. Employing an energy meter sensor to infer the expended energy from air conditioner excluding remain devices, as shown in Figure 2.

- Step 1: Six separate hours were specified throughout the day.

- Step 2: An energy meter installed.

- Step 3: Record the maximum and minimum temperature for the day.

- Step 4: A temperature sensor is used to measure hourly temperature in six specified hours.

- Step 5: Adjust the air conditioning cooling temperature to $25^{\circ} \mathrm{C}$.

- Step 6: Record the amount of cooling energy consumed via:

a. Consumed energy per specified hour.

b. Energy consumption is measured throughout the day by adding up the consumption of the specified six hours. 
- Step 7: Repeat Step 3 to step 6 for 20 days.

- Step 8: Calculate cooling power consumption during the 20 days.

To quantify energy utilized and due to temperature variation, all day long six separate hours were specified throughout the day, 3 hours in the morning, and 3 hours in the evening with a time difference between each hour. In which the measurement captures the difference in the energy spent in different temperatures throughout the day. An energy meter is established to measure the electricity consumption of the air conditioning if activated through the specified hours. Then, air conditioning operating cooling temperature is installed at $25^{\circ} \mathrm{C}$ due to proving that the efficiency of the air conditioner increases at this degree, and it is the ideal temperature reducing the energy consumption of refrigeration and appropriate for room occupants. Simultaneously, the amount of cooling energy expended per hour is recorded, from which the energy is calculated over six hours per day. Consequently, phase 2 was established to compare its results with phase 1, and to observe the variation in the amount of cooling energy consumed.

Phase 2: This phase aims to reduce cooling energy in architecture identical to phase one and engross in 20 days. Established on an automatic air conditioner control compact with cooling temperature setpoint at $25^{\circ} \mathrm{C}$. Controlling is based on the human detection system of the room based on streaming data using a live broadcast camera, thus image analysis to infer the presence of human factors, see Figure 2. Accordingly, give a decision to operate the air conditioning. The proposed model reduced cooling energy by $59 \%$, as illustrated in the result section.

- Step 1: Six separate hours were specified throughout the day.

- Step 2: An energy meter installed.

- Step 3: Record the maximum and minimum temperature for the day.

- Step 4: A temperature sensor is used to measure the hourly temperature in the specified hours.

- Step 5: A camera installed, navigating the adopted space.

- Step 6: The system starts to operate automatically at every specified hour.

- Step 7: Human detection activated, if:

a. Occupant detected, then go to step 8.

b. Occupant not detected, and then sends turn-off signal to AC.

- Step 8: Occupant presence state activated, then measure room temperature if:

a. Temperature $<25^{\circ} \mathrm{C}$, then $\mathrm{AC}$ off.

b. Temperature $>25^{\circ} \mathrm{C}$, then send turn- on signal to AC.

- Step 9: Record room occupant entry and exit times.

- Step 10: Record the amount of cooling energy consumed via:

a. Consumed energy per specified hour.

b. Calculate energy consumption throughout the day of the specified six hours.

- Step 11: Repeat step 3 to step 10 for 20 days.

- Step 12: Calculate cooling power consumption during the 20 days.

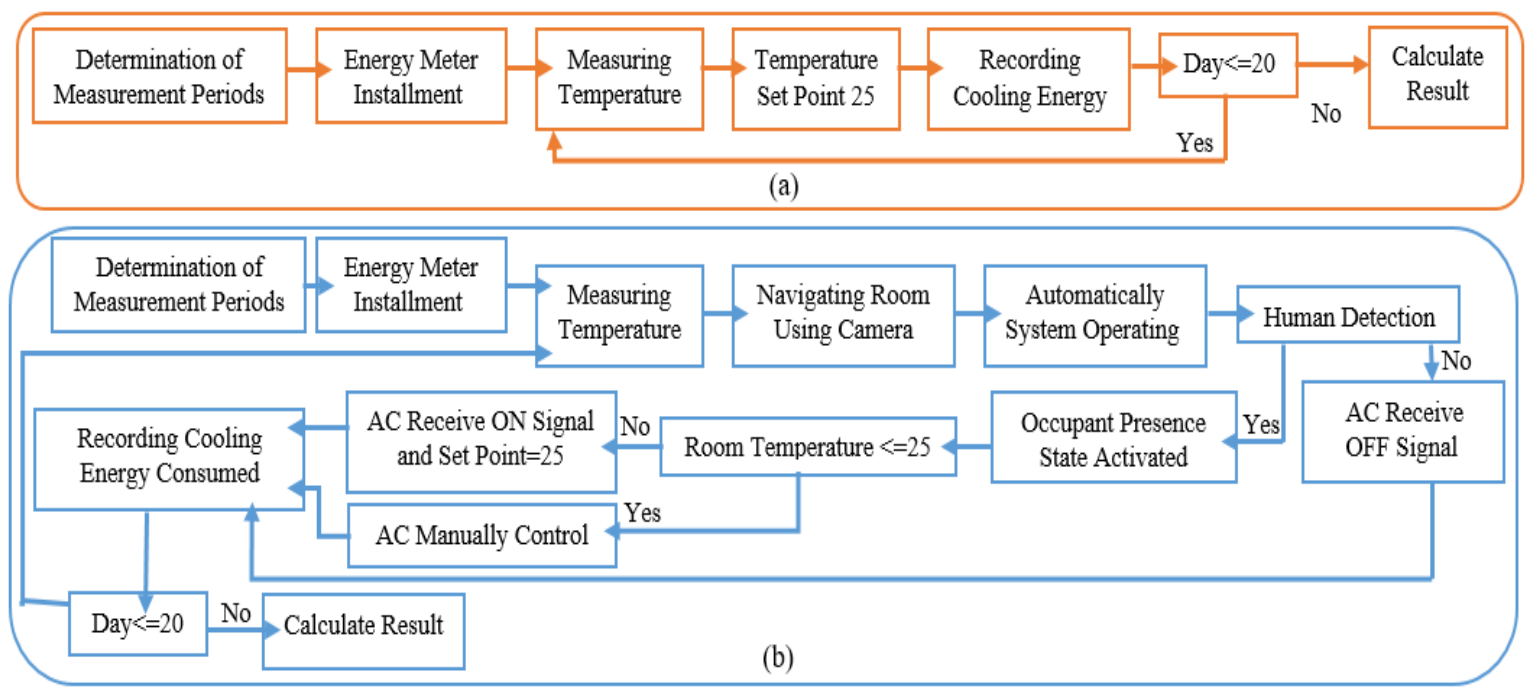

Figure 2. Proposed model, (a) Phase 1, (b) Phase 2 
As previously mentioned, the hours selected as the hours specified in phase 1 with the same distribution. To perceive the variation in electricity consumption under applying the system. An energy meter is installed to measure the electricity consumption of the air conditioning if it turned on. Supplementary, a camera is installed to navigating the adopted space for observing the presence of the human factor. After setting all the devices, the system starts to operate automatically at every specified hour. Posteriorly, the camera is activated to observe any occupant in a room after starting the system operation interacting with AC automatic control.

The occupant detection state determines the nature of the system operation. The occupant presence active state requires the system to measure room temperature to operate one of two decisions; if the measured temperature is greater than $25^{\circ} \mathrm{C}$, the system sends a turn-on signal to the AC. Otherwise, if the measured temperature is less than $25^{\circ} \mathrm{C}$, the $\mathrm{AC}$ remains off unless the occupant of the room operates it manually. Room occupant entry and exit times were recorded for every specified hour. The number of entry times has been calculated for room occupant, at that point estimating the all-out time spent in the room during each hour. To perceive the full duration of the air conditioner operation and remark its impact on the spent cooling energy. After adjusting all the necessary environment to implement the proposed model and record the required data of phase 2. Comparison of the results of phase 1 and phase 2 was addressed, the proposed model reduced cooling energy by $59 \%$, which are detailed illustrated in the results and discussion section.

\section{RESULT AND DISCUSSION}

The effectiveness of the proposed model that employed occupancy-based combined with a temperature setpoint strategy presented in this section, illustrating each phase results and the results of applying human detection using improved YOLO.

\subsection{Proposed model}

The proposed model results were provided over twenty days in Table 2 . The results are separated into two stages, stage one introduced results for expended cooling energy with no conditions showing that total cooling energy consumed in six hours per day ranges from 8.9 to $17.03 \mathrm{kWh}$. In the wake of ascertaining the energy expended for twenty days, it is found that the aggregate sum of cooling energy $276.01 \mathrm{kWh}$ in phase one. The energy employed under model conditions is compared to estimate potential savings associated with occupancy-based control merged with the temperature setpoint.

Table 2. Phase 1 and phase 2 daily cooling energy consumption illustrating energy savings

\begin{tabular}{cccc}
\hline \multirow{2}{*}{ Days } & Phase 1 & Phase 2 & Energy Savings(kWh) \\
& Cooling energy consumed Per Day $(\mathrm{kWh})$ & Cooling energy consumed Per Day $(\mathrm{kWh})$ & 5.62 \\
1 & 10.12 & 4.5 & 3.64 \\
2 & 11.09 & 7.45 & 6.19 \\
3 & 8.90 & 2.71 & 4.88 \\
4 & 11.88 & 7 & 6.94 \\
5 & 12 & 5.06 & 9.5 \\
6 & 15.38 & 5.88 & 6.44 \\
7 & 12.75 & 6.31 & 7.49 \\
8 & 12.74 & 5.25 & 8.95 \\
9 & 14.57 & 5.62 & 8.32 \\
10 & 15.27 & 6.95 & 8.78 \\
11 & 17.03 & 8.25 & 11.95 \\
12 & 16.83 & 4.88 & 10.31 \\
13 & 15.97 & 5.66 & 11.36 \\
14 & 16.04 & 4.68 & 10.12 \\
15 & 16.09 & 5.97 & 7.87 \\
16 & 13.19 & 5.32 & 11.17 \\
17 & 15.23 & 4.06 & 7.43 \\
18 & 12.54 & 5.11 & 7.79 \\
19 & 15.33 & 7.54 & 8.81 \\
20 & 13.06 & 4.25 & 163.56 \\
\hline
\end{tabular}

The results showed that cooling energy decreases by more than anticipated as the amount of reduced energy reached 59\% savings as illustrated in Figure 3. Cooling energy consumed in each day of phase 2 ranged from $4.06 \mathrm{kWh}$ to $8.25 \mathrm{kWh}$ and the aggregate sum of cooling energy $112.45 \mathrm{kWh}$. To better clarify the results, Table 3 and Table 4 illustrate cooling energy expended in each hour specified in the post 
Meridiem and Ante Meridiem periods over twenty days. The listed results exhibit cooling energy in phase 1 alongside phase 2 day by day, besides the amount of energy saving among the two phases.

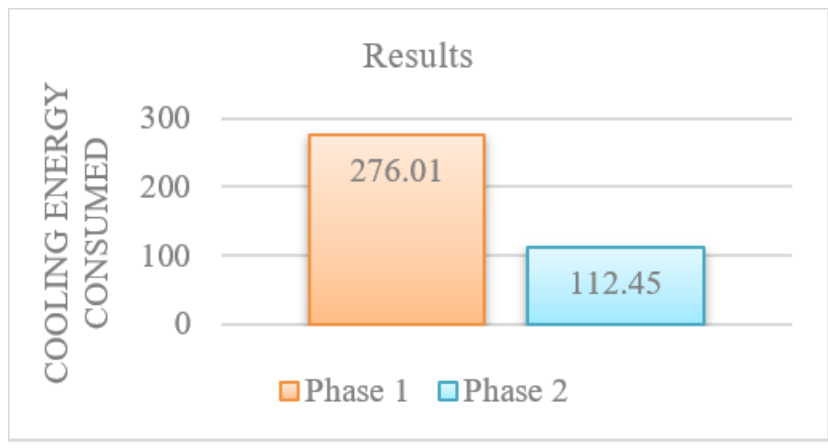

Figure 3. Variance among phase 1 and phase 2 results

Table 3. Cooling energy consumed during post meridiem specified periods showing energy savings.

*None means no process exists in that period

\begin{tabular}{|c|c|c|c|c|c|c|c|c|c|}
\hline \multirow[b]{3}{*}{ Day } & \multicolumn{3}{|c|}{ Hour 1} & \multicolumn{3}{|c|}{ Hour 2} & \multicolumn{3}{|c|}{ Hour 3} \\
\hline & Phase 1 & Phase2 & & Phase 1 & Phase2 & & Phase 1 & Phase2 & \\
\hline & $\begin{array}{c}\text { Cooling } \\
\text { energy } \\
\text { consumed } \\
(\mathrm{kWh})\end{array}$ & $\begin{array}{c}\text { Cooling } \\
\text { energy } \\
\text { consumed } \\
(\mathrm{kWh})\end{array}$ & $\begin{array}{c}\text { Energy } \\
\text { Savings } \\
(\mathrm{kWh})\end{array}$ & $\begin{array}{c}\text { Cooling } \\
\text { energy } \\
\text { consumed } \\
(\mathrm{kWh})\end{array}$ & $\begin{array}{c}\text { Cooling } \\
\text { energy } \\
\text { consumed } \\
(\mathrm{kWh})\end{array}$ & $\begin{array}{c}\text { Energy } \\
\text { Savings } \\
(\mathrm{kWh})\end{array}$ & $\begin{array}{l}\text { Cooling } \\
\text { energy } \\
\text { consumed } \\
(\mathrm{kWh})\end{array}$ & $\begin{array}{c}\text { Cooling } \\
\text { energy } \\
\text { consumed } \\
(\mathrm{kWh})\end{array}$ & $\begin{array}{c}\text { Energy } \\
\text { Savings } \\
(\mathrm{kWh})\end{array}$ \\
\hline 1 & 2.86 & 1.63 & 1.23 & 2.60 & 0.83 & 1.77 & 2.47 & 1.12 & 1.35 \\
\hline 2 & 2.54 & 0.88 & 1.66 & 2.40 & 2.11 & 0.29 & 2.27 & 1.13 & 1.14 \\
\hline 3 & 2.50 & 2.63 & - & 2.45 & 1.38 & 1.07 & None & 2.40 & - \\
\hline 4 & 2.60 & 0.89 & 1.71 & 2.51 & 1.26 & 1.25 & None & None & - \\
\hline 5 & 2.75 & 1.93 & 0.82 & 2.53 & 1.25 & 1.28 & 2.38 & None & 2.38 \\
\hline 6 & 2.89 & None & 2.89 & 2.74 & None & 2.74 & 2.55 & 2.25 & 0.3 \\
\hline 7 & 2.96 & 1.92 & 1.04 & 2.74 & 2.92 & - & 2.54 & 2.22 & 0.32 \\
\hline 8 & 2.93 & 2.36 & 0.57 & 2.72 & 2.85 & - & 2.51 & 0.39 & 2.12 \\
\hline 9 & 2.77 & 0.63 & 2.14 & 2.85 & 1.40 & 1.45 & 2.65 & 1.62 & 1.03 \\
\hline 10 & 2.77 & 1.82 & 0.95 & 2.67 & 1.84 & 0.83 & 2.52 & 0.67 & 1.85 \\
\hline 11 & 3.14 & 2.54 & 0.6 & 2.95 & 1.05 & 1.9 & 2.92 & 1.65 & 1.27 \\
\hline 12 & 3.27 & 0.69 & 2.58 & 3.10 & 1.28 & 1.82 & 2.85 & None & 2.85 \\
\hline 13 & 3.16 & 1.17 & 1.99 & 2.88 & 1.94 & 0.94 & 2.64 & None & 2.64 \\
\hline 14 & 3.02 & 1.78 & 1.24 & 2.87 & 1.34 & 1.53 & 2.63 & 1.08 & 1.55 \\
\hline 15 & 3.17 & 1.17 & 2 & 3.05 & 1.30 & 1.75 & 2.60 & 0.76 & 1.84 \\
\hline 16 & 3.03 & 1.25 & 1.78 & 2.88 & 2.45 & 0.43 & None & None & - \\
\hline 17 & 2.90 & 1.14 & 1.76 & 2.79 & 1.66 & 1.13 & 2.45 & 1.26 & 1.19 \\
\hline 18 & None & 1.78 & - & 2.70 & 1.67 & 1.03 & 2.50 & 1.74 & 0.76 \\
\hline 19 & 2.85 & 2.14 & 0.71 & 2.69 & 2.63 & 0.06 & 2.59 & 0.67 & 1.92 \\
\hline 20 & 3.01 & 2.08 & 0.93 & 2.90 & 1.70 & 1.2 & None & 2.11 & - \\
\hline Total & 52.62 & 26.02 & 26.6 & 49.56 & 27.09 & 22.47 & 41.07 & 16.56 & 24.51 \\
\hline
\end{tabular}

Subsequently, the total cooling energy for both phases one and two were calculated, and the total energy saved between the use of the two phases was calculated for each hour. For the post Meridiem period, total energy utilized for hours 1, 2, and 3 through phase 1 showing the results 52.62, 49.56, and $41.07 \mathrm{kWh}$ in order. In contradiction to the results of phase 2, showing 26.02, 27.09, and $16.56 \mathrm{kWh}$. Consequently, remarkable results have emerged for saved wasted energy on about 26.6, 22.47, and $24.51 \mathrm{kWh}$.

Meantime the same lines to clarify Ante Meridiem, total energy consumed for hours 4, 5, and 6 through phase 1 showing the results $42.3,47.17$ and $43.29 \mathrm{kWh}$ in order. Differencing with the results of phase 2, showing 21.99, 14.15, and 6.29 $\mathrm{kWh}$. As remarked, the results for saved cooling energy about 20.31, 32.67, and $37 \mathrm{kWh}$. Then Figure 4 illustrates the diversity in cooling energy consumption between phase 1 and phase 2 in each specified hour. From this, the results show the extend of savings upon depending the proposed strategy. 
Table 4. Cooling energy consumed during ante meridiem specified periods showing energy savings

* NO indicates that a human detection occurs in that period but AC is not manually opened

\begin{tabular}{|c|c|c|c|c|c|c|c|c|c|}
\hline \multirow[b]{2}{*}{ Day } & \multicolumn{3}{|c|}{ Hour 4} & \multicolumn{3}{|c|}{ Hour 5} & \multicolumn{3}{|c|}{ Hour 6} \\
\hline & $\begin{array}{c}\text { Phase } 1 \\
\text { Cooling } \\
\text { energy } \\
\text { consumed } \\
(\mathrm{kWh})\end{array}$ & $\begin{array}{c}\text { Phase2 } \\
\text { Cooling } \\
\text { energy } \\
\text { consumed } \\
(\mathrm{kWh})\end{array}$ & $\begin{array}{c}\text { Energy } \\
\text { Savings } \\
(\mathrm{kWh})\end{array}$ & $\begin{array}{c}\text { Phase } 1 \\
\text { Cooling } \\
\text { energy } \\
\text { consumed } \\
(\mathrm{kWh})\end{array}$ & $\begin{array}{c}\text { Phase2 } \\
\text { Cooling } \\
\text { energy } \\
\text { consumed } \\
(\mathrm{kWh})\end{array}$ & $\begin{array}{c}\text { Energy } \\
\text { Savings } \\
(\mathrm{kWh})\end{array}$ & $\begin{array}{c}\text { Phase } 1 \\
\text { Cooling } \\
\text { energy } \\
\text { consumed } \\
(\mathrm{kWh})\end{array}$ & $\begin{array}{c}\text { Phase } 2 \\
\text { Cooling } \\
\text { energy } \\
\text { consumed } \\
(\mathrm{kWh})\end{array}$ & $\begin{array}{c}\text { Energy } \\
\text { Savings } \\
(\mathrm{kWh})\end{array}$ \\
\hline 1 & 2.26 & 2.32 & - & 2.19 & 0.92 & 1.27 & 2.04 & 2.38 & - \\
\hline 2 & 2.10 & 2.40 & - & 2.01 & 1.70 & 0.31 & 1.87 & 1.63 & 0.24 \\
\hline 3 & 2.18 & 1.14 & 1.04 & 2.15 & None & 2.15 & 2.12 & 0.19 & 1.93 \\
\hline 4 & 2.28 & 2.27 & 0.01 & 2.27 & 1.06 & 1.21 & 2.22 & 1.52 & 0.7 \\
\hline 5 & 2.34 & 2.39 & - & 2.17 & 1.44 & 0.73 & 2.17 & 0.44 & 1.73 \\
\hline 6 & 2.52 & 1.62 & 0.9 & 2.38 & 1.67 & 0.71 & 2.30 & 0.34 & 1.96 \\
\hline 7 & 2.53 & None & 2.53 & 2.36 & 2.17 & 0.19 & 2.36 & None & 2.36 \\
\hline 8 & 2.50 & 1.30 & 1.2 & 2.40 & 1.20 & 1.2 & 2.40 & None & 2.4 \\
\hline 9 & 2.50 & 1.97 & 0.53 & 2.40 & None & 2.4 & 1.40 & $\mathrm{NO}$ & 1.4 \\
\hline 10 & 2.50 & 1.58 & 0.92 & 2.41 & 1.04 & 1.37 & 2.40 & NO & 2.4 \\
\hline 11 & 2.76 & 1.28 & 1.48 & 2.66 & 0.54 & 2.12 & 2.60 & 1.19 & 1.41 \\
\hline 12 & 2.65 & 2.10 & 0.55 & 2.54 & 0.81 & 1.73 & 2.42 & NO & 2.42 \\
\hline 13 & 2.47 & 1.26 & 1.21 & 2.45 & 0.31 & 2.14 & 2.37 & 0.98 & 1.39 \\
\hline 14 & 2.56 & 0.48 & 2.08 & 2.43 & None & 2.43 & 2.53 & NO & 2.53 \\
\hline 15 & 2.53 & 1.57 & 0.96 & 2.31 & 1.17 & 1.14 & 2.43 & NO & 2.43 \\
\hline 16 & 2.53 & 1.62 & 0.91 & 2.36 & $\mathrm{NO}$ & 2.36 & 2.39 & None & 2.39 \\
\hline 17 & 2.40 & None & 2.4 & 2.39 & NO & 2.39 & 2.30 & None & 2.3 \\
\hline 18 & 2.52 & 1.70 & 0.82 & 2.47 & NO & 2.47 & 2.35 & $\mathrm{NO}$ & 2.35 \\
\hline 19 & 2.52 & 2.10 & 0.42 & 2.29 & NO & 2.29 & 2.39 & NO & 2.39 \\
\hline 20 & 2.35 & None & 2.35 & 2.53 & 0.47 & 2.06 & 2.27 & None & 2.27 \\
\hline Total & 42.3 & 21.99 & 20.31 & 47.17 & 14.5 & 32.67 & 43.29 & 6.29 & 37 \\
\hline
\end{tabular}

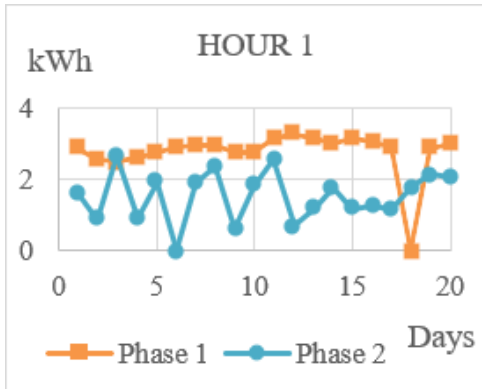

(a)

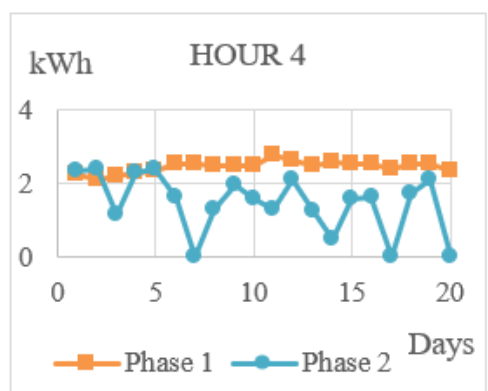

(d)

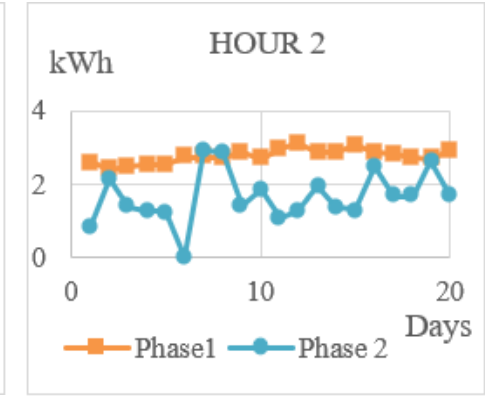

(b)

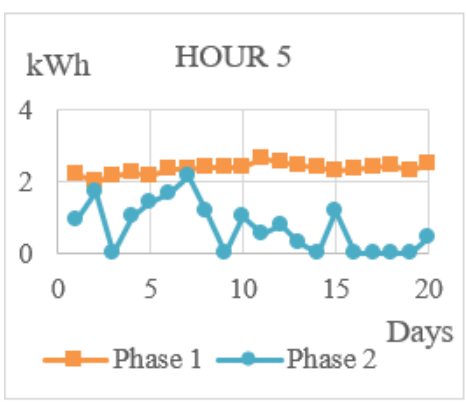

(e)

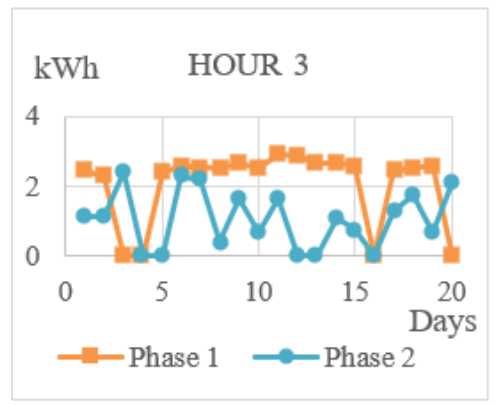

(c)

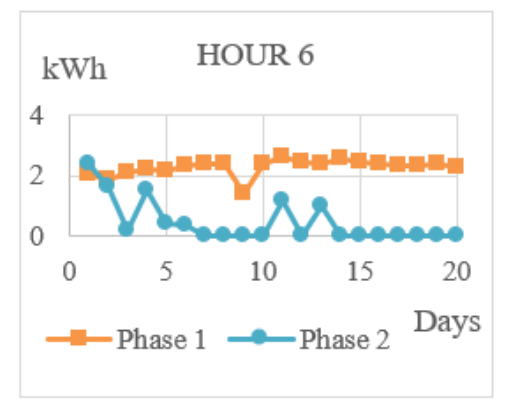

(f)

Figure 4. Phase 1 and phase 2 daily cooling energy consumption for each specified hour, (a) Hour 1, (b) Hour 2, (c) Hour 3, (d) Hour 4, (e) Hour 5, (f) Hour 6

\subsection{Human detection based on improved YOLO}

To obtain the best results in detecting the presence of the human factor using YOLO, a preprocessing step was added to improve the detection results. Experience has shown that the pre-processing 
step before the direct use of YOLO enhances the required image information. The results showed that the average YOLO detection reaches $71.17 \%$, with the reverse of improved YOLO reaches $92.37 \%$. The average improvement of use these algorithms on the image before the detection stage of the human factor using YOLOV3 is $21.2 \%$, as shown in Figure 5.

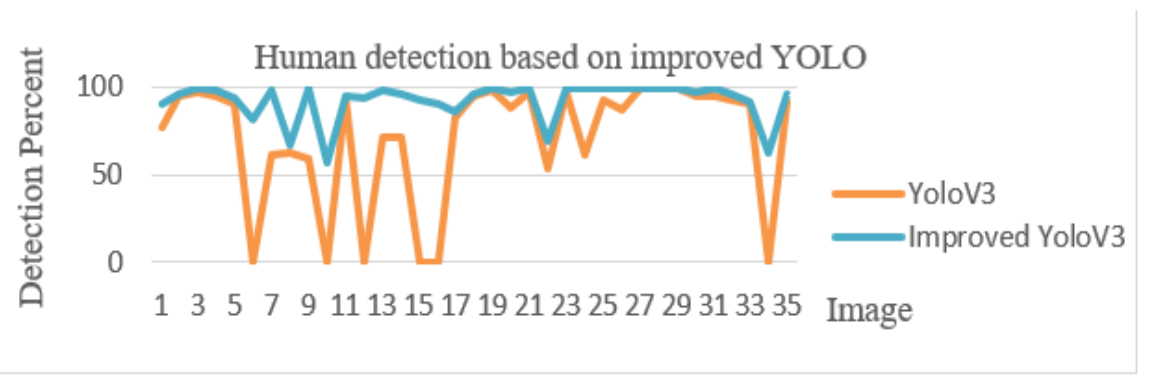

Figure 5. Comparison between YOLOv3 and improved YOLOv3 detection

\section{CONCLUSION}

This research built an occupancy-based model combined with a constant temperature setpoint for reducing cooling energy in buildings. This strategy employing human detection for detecting humans using Improved YOLO consolidated with $25^{\circ} \mathrm{C}$ as a temperature setpoint. It was implemented in two phases in a single room of an Egyptian single-family residence. The strategy is performed in two different phases to investigate the cooling energy consumed with and without the applied conditions for this strategy. The findings of the proposed model effectively reduce cooling energy under built model conditions showed that cooling energy decreases by more than anticipated as the amount of lessened energy reached 59\% savings. To make this strategy deliver the most dependable results, its refined human detection, the detection measurement of YOLO was improved by applying pre-processing algorithms to reach an average improvement of $21.2 \%$.

\section{REFERENCES}

[1] Y. Chen, F. Zhang, and U. Berardi, "Day-ahead prediction of hourly subentry energy consumption in the building sector using pattern recognition algorithms," Energy, vol. 211, p. 118530, November 2020, doi: 10.1016/j.energy.2020.118530.

[2] A. Al-Saggaf, H. Nasir, and M. Tahaa, "Quantitative approach for evaluating the building design features impact on cooling energy consumption in hot climates," Energy and Buildings, vol. 211, p. 109802, March 2020, doi: 10.1016/j.enbuild.2020.109802.

[3] Nasruddin, Sholahudin, P. Satrio, T. M. I. Mahlia, N. Giannetti, and K. Saitoc, "Optimization of HVAC system energy consumption in a building using artificial neural network and multi-objective genetic algorithm," Sustainable Energy Technologies and Assessments, vol. 35, pp. 48-57, October 2019, doi: 10.1016/j.seta.2019.06.002.

[4] N. H. Motlagh, M. Mohammadrezaei, J. Hunt, and B. Zakeri, "Internet of Things (IoT) and the Energy Sector," Energies, vol. 13, no. 2, p. 494, 2020, doi: 10.3390/en13020494.

[5] National Center for Housing and Building Research, Egyptian code to improve the energy efficiency of residential buildings. Cairo, 2008.

[6] S. Attia, A. Evrard, and E. Gratia, "Development of benchmark models for the Egyptian residential buildings sector," Applied Energy, vol. 94, pp. 270-284, 2012, doi: 10.1016/j.apenergy.2012.01.065.

[7] A. Ragab and A. Abdelrady, "Impact of Green Roofs on Energy Demand for Cooling in Egyptian Buildings," Sustainability, vol. 12, no. 14, p. 5729, 2020, doi: 10.3390/su12145729.

[8] A. M. Elharidi, P. G. Tuohy, and M. A. Teamah, "The energy and indoor environmental performance of Egyptian offices: Parameter analysis and future policy," Energy and Buildings, vol. 158, pp. 431-452, 2018, doi: 10.1016/j.enbuild.2017.10.035.

[9] N. S. Lopez, J. Gonzaga, and L. A. G. Lim, "Energy audit and analysis of the electricity consumption of an educational building in the Philippines for smart consumption," 2017 IEEE 9th International Conference on Humanoid, Nanotechnology, Information Technology, Communication and Control, Environment and Management (HNICEM), 2017, pp. 1-4, doi: 10.1109/HNICEM.2017.8269505.

[10] M. Q. Taha, "Advantages and recent advances of smart energy grid," Bulletin of Electrical Engineering and Informatics (BEEI), vol. 9, no. 5, pp. 1739-1746, 2020, doi: 10.11591/eei.v9i5.2358. 
[11] M. Shamshiri, C. K. Gan, K. A. Baharin, and M. A. M. Azman, "IoT-based electricity energy monitoring system at Universiti Teknikal Malaysia Melaka," Bulletin of Electrical Engineering and Informatics (BEEI), vol. 8, no. 2, pp. 683-689, 2019, doi: 10.11591/eei.v8i2.1281.

[12] D. Casado-Mansilla, et al., "A Human-Centric \& Context-Aware IoT Framework for Enhancing Energy Efficiency in Buildings of Public Use," in IEEE Access, vol. 6, pp. 31444-31456, 2018, doi: 10.1109/ACCESS.2018.2837141.

[13] D. Casado-Mansilla, et al., "Socio-Economic Effect on ICT-Based Persuasive Interventions "Towards Energy Efficiency in Tertiary Buildings," Energies, vol. 13, no. 7, p. 1700, 2020, doi: 10.3390/en13071700.

[14] M. Krarti, "Evaluation of occupancy-based temperature controls on energy performance of KSA residential buildings," Energy and Buildings, vol. 220, p. 110047, 2020, doi: 10.1016/j.enbuild.2020.110047.

[15] A. Ghahramani, K. Zhang, K. Dutta, Z. Yang, and B. Becerik-Gerberb, "Energy savings from temperature setpoints and deadband: Quantifying the influence of building and system properties on savings," Applied Energy, vol. 165, pp. 930-942, 2016, doi: 10.1016/j.apenergy.2015.12.115.

[16] T. Hoyt, E. Arens, and H. Zhang, "Extending air temperature setpoints: Simulated energy savings and design considerations for new and retrofit buildings," Building and Environment, vol. 88, pp. 89-96, 2015, doi: 10.1016/j.buildenv.2014.09.010.

[17] Y. Xue, K. Zhao, Y. Qian, and J. Gea, "Improved operating strategy for air-conditioning systems based on the indoor occupancy rate," Journal of Building Engineering, vol. 29, p. 101196, 2020, doi: 10.1016/j.jobe.2020.101196.

[18] L. Nikdel, K. Janoyan, S. D. Bird, and S. E. Powers, "Multiple perspectives of the value of occupancy-based HVAC control systems," Building and Environment, vol. 129, pp. 15-25, 2018, doi: 10.1016/j.buildenv.2017.11.039.

[19] ECP306/1-2005, The Egyptian Residential Buildings Energy Code. Housing and Building National Research Center, 2005.

[20] A. Standard, "Energy Standard for Buildings Except Low-Rise Residential Buildings," 90.1-2013.

[21] A. S. Adly, "Climate Change and Energy Decision Aid Systems for the Case of Egypt," Understanding Complex Systems Climate Change and Energy Dynamics in the Middle East, pp. 79-107, 2019, doi: 10.1007/978-3-03011202-8_4.

[22] Z. Wang and T. Hong, "Learning occupants' indoor comfort temperature through a Bayesian inference approach for office buildings in United States," Renewable and Sustainable Energy Reviews, vol. 119, p. 109593, 2020, doi: 10.1016/j.rser.2019.109593.

[23] D. Trivedi and V. Badarla, "Occupancy detection systems for indoor environments: A survey of approaches and methods," Indoor and Built Environment, vol. 29, no. 8, pp. 1053-1069, 2020, doi: 10.1177/1420326X19875621.

[24] J. Ahmad, H. Larijani, R. Emmanuel, M. Mannion, and A. Javed, "Occupancy detection in non-residential buildings-A survey and novel privacy preserved occupancy monitoring solution," Applied Computing and Informatics, 2020, doi: 10.1016/j.aci.2018.12.001/full/html.

[25] S. Ren, K. He, R. Girshick, and J. Sun, "Faster R-CNN: Towards Real-Time Object Detection with Region Proposal Networks," in IEEE Transactions on Pattern Analysis and Machine Intelligence, vol. 39, no. 6, pp. 1137 1149, 1 June 2017, doi: 10.1109/TPAMI.2016.2577031.

[26] W. Liu, et al., "SSD: Single Shot MultiBox Detector," Computer Vision-ECCV 2016 Lecture Notes in Computer Science, pp. 21-37, 2016, doi: 10.1007/978-3-319-46448-0_2.

[27] J. Redmon and A. Farhadi, "YOLOv3: An incremental improvement," arXiv preprint, 2018.

[28] J. Huang et al., "Speed/Accuracy Trade-Offs for Modern Convolutional Object Detectors," 2017 IEEE Conference on Computer Vision and Pattern Recognition (CVPR), 2017, pp. 3296-3297, doi: 10.1109/CVPR.2017.351.

[29] S. Ren, "Faster r-cnn: Towards real-time object detection with region proposal networks," arXiv preprint arXiv:1506.01497, pp. 91-99, 2015.

[30] P. Bharati and A. Pramanik, "Deep Learning Techniques-R-CNN to Mask R-CNN: A Survey," Computational Intelligence in Pattern Recognition Advances in Intelligent Systems and Computing, vol. 999, pp. 657-668, 2020, doi: 10.1007/978-981-13-9042-5_56. 